\title{
Surgical Management of Bicornual Uterine Prolapse in a Siamese Cat: A Case Report
}

\author{
WK Kimani* and SW Mbugua \\ Department of Clinical Studies, University of Nairobi, P.O. Box 29053-00625, Nairobi, Kenya \\ *Corresponding author: kuriakimani49@gmail.com
}

\begin{abstract}
\begin{tabular}{llll}
\hline Article History: 19-615 & Received: June 26, 2019 & Revised: September 18, 2019 & Accepted: September 28, 2019 \\
\hline
\end{tabular}
ABSTRACT

Uterine prolapse is a rare condition in cats that can be managed by performing either an external hysterectomy or manual reduction followed by ovariohysterectomy. This article describes surgical management of bilateral uterine prolapse in a queen. A one year old female, pluriparous Siamese cat (Felis catus) with no past history of dystocia and weighing 2.8 $\mathrm{kg}$ was presented to Andys Veterinary hospital, Nairobi, Kenya with a protruding mass through the vulval. The queen had a history of recent queening and had delivered three kittens a week earlier. The owner noticed the protruding mass about 24 hours after the delivery of the last neonate. A few days later, the cat was not suckling the kittens well and was in appetent. As a sequel to this, two kittens died. After a week, the protruding mass had a pungent smell and the client presented the cat to the hospital. Complete bilateral uterine prolapse was diagnosed after a visual examination and palpation of the mass. The uterus was swollen, had necrotic areas and debris. Accordingly, a two staged ovariohysterectomy was opted for to manage the case. An internal ovariectomy was first done via a ventral midline celiotomy followed by an external hysterectomy. Post-operative management included pain medication and antibiotic therapy and the patient recovered well and was discharged after 2 days. The skin sutures were removed 10 days postoperatively. The cat recovered uneventfully with no further complications reported by the owner. In conclusion, this article shows that when the prolapsed uterus is swollen, damaged and necrotic, a two staged ovariohysterectomy should be the method of treatment and the outcome is good despite the duration of the condition.
\end{abstract}

Key words: Felis catus, Bilateral uterine prolapse

\section{INTRODUCTION}

Uterine prolapse by definition is when the uterus turns inside out and passes through the cervix into the vagina (MacPhail, 2013, Deroy et al., 2015) but can occur without mucosal eversion (Bigliardi et al., 2014). Uterine prolapse in cats is an uncommon complication of parturition. It contributed to $0.8 \%$ of the total genital system surgical problems in cats (Senna et al., 2015). It can occur instantly or up to 48 hours after delivery of the last kitten or after a prolonged queening or abortion (Ozyurtlu and Kaya, 2004, Deroy et al., 2015, Sabuncu et al., 2015, Valentine et al 2015, Jarolmasjed, 2017); but can occur after a normal parturition (Bigliardi et al., 2014).

The condition has been reported during the process of parturition in a cat (Ucmak et al., 2018) and in a nonpregnant cat (Valentine et al., 2015). Complete uterine prolapse is reported infrequently in cats aged between 10 months to 6 years (Ozyurtlu and Kaya, 2004, Ucmak et al., 2018). It has an incidence of less than $0.03 \%$ (Senna et al.,
2015) accounting for $0.6 \%$ of the maternal causes of difficulty in queening (Deroy et al., 2015, Jarolmasjed, 2017). Both multiparous and primiparous queens have been reported to suffer from uterine prolapse (Bigliardi et al., 2014). Further, the condition is seen more in cats than in dogs (Jackson, 2004).

Etiology of this condition is unknown (Jarolmasjed, 2017); but it is suggested that it may be a sequel of dystocia and increased straining. Causes of dystocia in cats include the following: incomplete placental separation, prolonged queening, discomfort or pain after queening (Deroy et al., 2015, Jarolmasjed, 2017). Diagnosis is easily made by visual examination of the prolapsed uterus (Ozyurtlu and Kaya, 2004, MacPhail, 2013, Jarolmasjed, 2017) while taking into consideration of the history (Bigliardi et al., 2014). In dogs, the severity of clinical signs and prognosis depend on the duration of the prolapse (Sathiamoorthy et al., 2013)

Described methods of treatment include: external hysterectomy; manual reduction through a laparotomy incision followed by ovariohysterectomy; reduction and

Cite This Article as: Kimani WK and SW Mbugua, 2020. Surgical management of bicornual uterine prolapse in a siamese cat: a case report. Int J Vet Sci, 9(2): 320-323. www.ijvets.com (@2020 IJVS. All rights reserved) 
repositioning of the prolapsed organ by abdominal palpation and use of an infusion (Ozyurtlu and Kaya, 2004, MacPhail, 2013). Prognosis improves if treatment is instituted rapidly (Ozyurtlu and Kaya, 2004, Mostachio et al., 2008) and is excellent following ovariohysterectomy if hemorrhage and shock are treated accordingly (MacPhail, 2013, Jarolmasjed, 2017).

\section{MATERIALS AND METHODS}

\section{Case history and diagnosis}

A one year old Siamese female cat weighing $2.8 \mathrm{~kg}$ was presented to the Andys Veterinary Hospital, Nairobi, Kenya, with a history of a protruding organ from the external genitalia. The cat had given birth to three kittens a week earlier. Two of them were delivered well without any incidence but the third kitten was delivered after about 24 hours. The owner noticed the protruding mass about 24 hours after the delivery of the last neonate. The cat was brought to the hospital seven days after the protruding mass was noticed and its condition had got worse with the mass having a pungent smell and the cat being inappetent. Bicornual uterine prolapse was diagnosed after a visual examination and palpation of the mass (Figure 1). On physical examination, the cat was depressed, hyperthermic at 40.1 degrees Celsius, slightly pale mucous membranes and dehydrated (approximately $5 \%$ ).

\section{Preoperative patient stabilization, preparation and anesthesia}

Blood smear showed neutrophilia. Because of financial constraints of the owner, complete blood count and blood biochemistry was not done. The respiratory and heart rate were both within normal ranges. The cat was rehydrated with lactated Ringers solution at $(55 \mathrm{~mL} / \mathrm{kg})$ administered through a $22 \mathrm{G}$ catheter. After stabilization of the patient for 6 hours, sedation was done using 2\% Xylazine (Xylazine, Agrar) at $1 \mathrm{mg} / \mathrm{kg}$ body weight intramuscularly. Induction of general anesthesia was done using 5\% Ketamine (Ketamax 50, Troikaa) at $10 \mathrm{mg} / \mathrm{kg}$ body weight intramuscularly. Ventral abdomen, perineal area and ventral part of the tail were clipped. The prolapsed tissue was cleaned with chlorhexidine and lavaged with normal saline solution to remove gross debris (Figure 2). A bandage (ProWrap, TRM) was placed around the tail and a purse-string suture using polyglycolic acid 910 No. 2/0 (Vicryl, Kenruss medics) was placed on the anus.

\section{Surgical technique}

The surgical operation was done in two phases: First internal ovariectomy followed by external hysterectomy. A midline abdominal incision was done to enable ovariectomy. The ovaries were in the caudal abdomen because of traction. The ovarian pedicle was not ruptured but the left and right ovarian arteries, suspensory ligaments and veins were elongated (Figure 3). Visualization of the urethral tubercle was done before external hysterectomy was done.

The prolapse was opened at the cranial part of the uterine body near the vulva to expose the uterine vessels which were then ligated using chromic catgut No.2/0. An incision was made cranial to the sutures to remove the uterine horns (Figure 4).

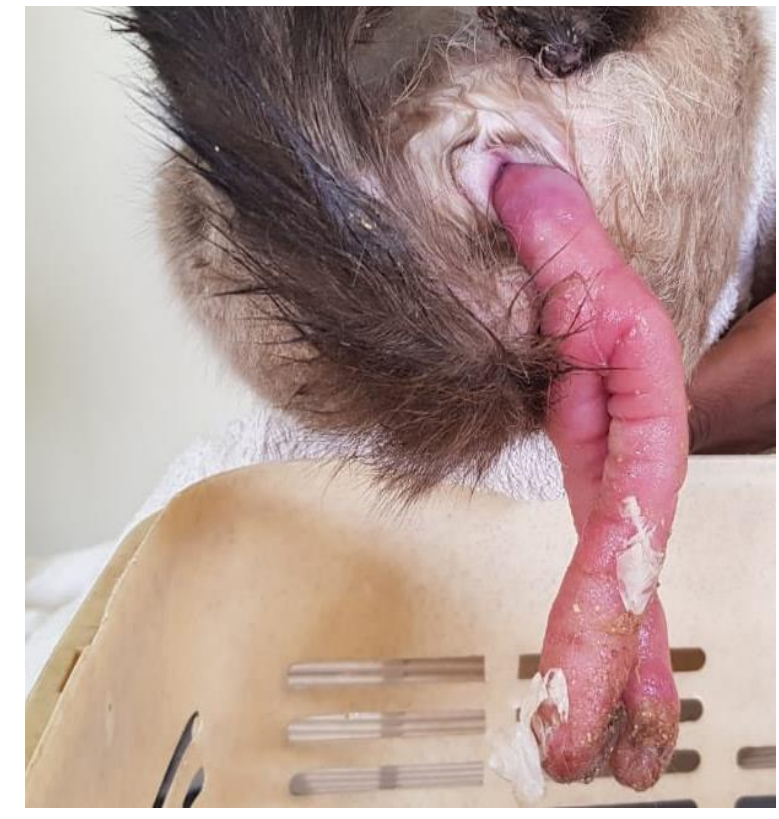

Fig. 1: Bicornual uterine prolapse. Note the contaminated, severely swollen uterus with necrotic areas shown by the arrow.

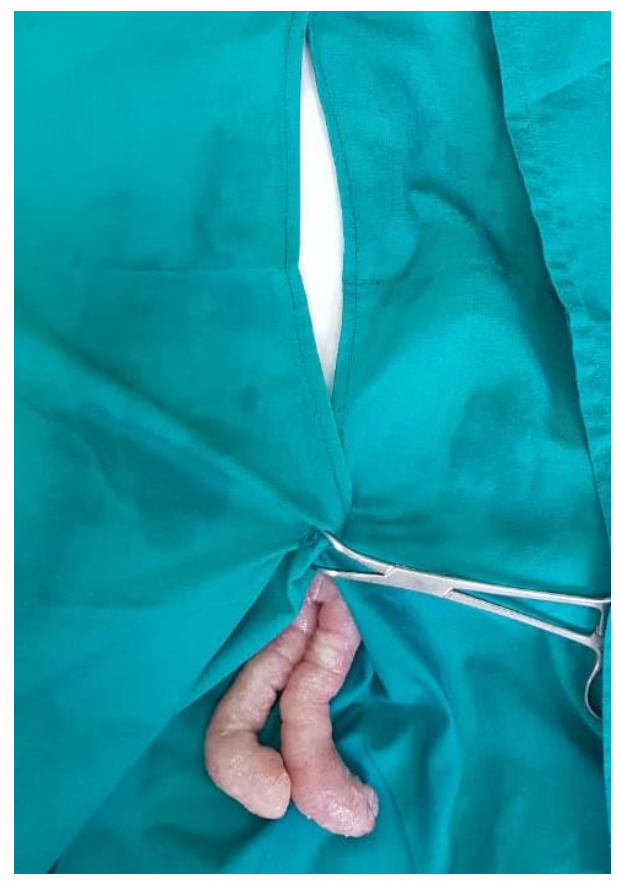

Fig. 2: A figure showing the complete, bilateral uterine prolapse. Note the swollen uterus and the devitalized tips of both horns.

The uterine stump was then closed with a simple continuous suture pattern and reduced into the abdomen via the pelvic canal. The peritoneum and linea alba were closed using polyglycolic acid 910 suture No. 2/0 (Vicryl, Kenruss medics) in a cruciate suture pattern. A subcuticular suture pattern was done using polyglycolic acid 910 suture No. 2/0 (Vicryl, Kenruss medics). The vulval lips were opposed with a horizontal mattress suture pattern without tightening to allow normal urination and vulval discharge. The suture was left in place for five days to prevent opening of vulva and possibly prolapse of the reduced uterine stump (Figure 5). 
Int J Vet Sci, 2020, 9(2): 320-323.

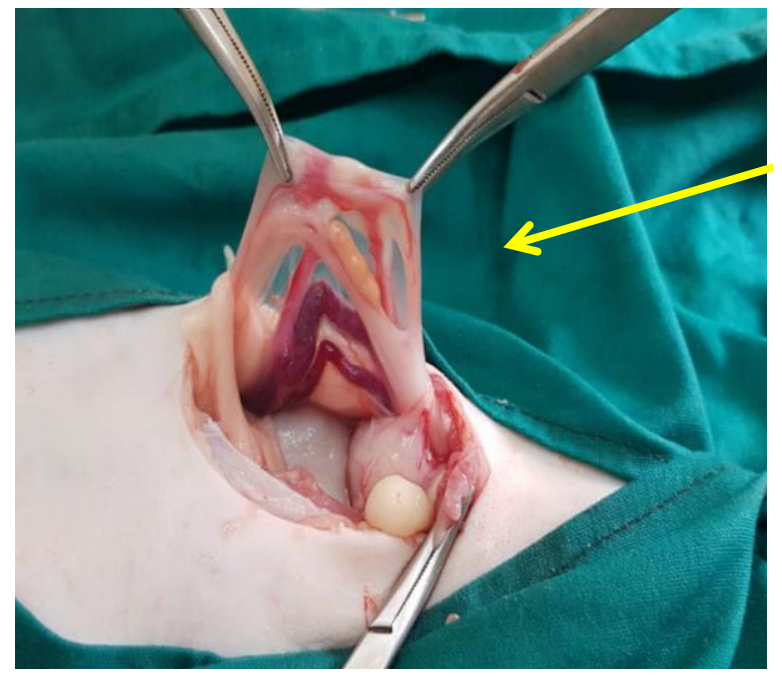

Fig. 3: Celiotomy incision to allow ovarietomy. Ovaries were located caudal abdomen. The arrow shows the ovary.

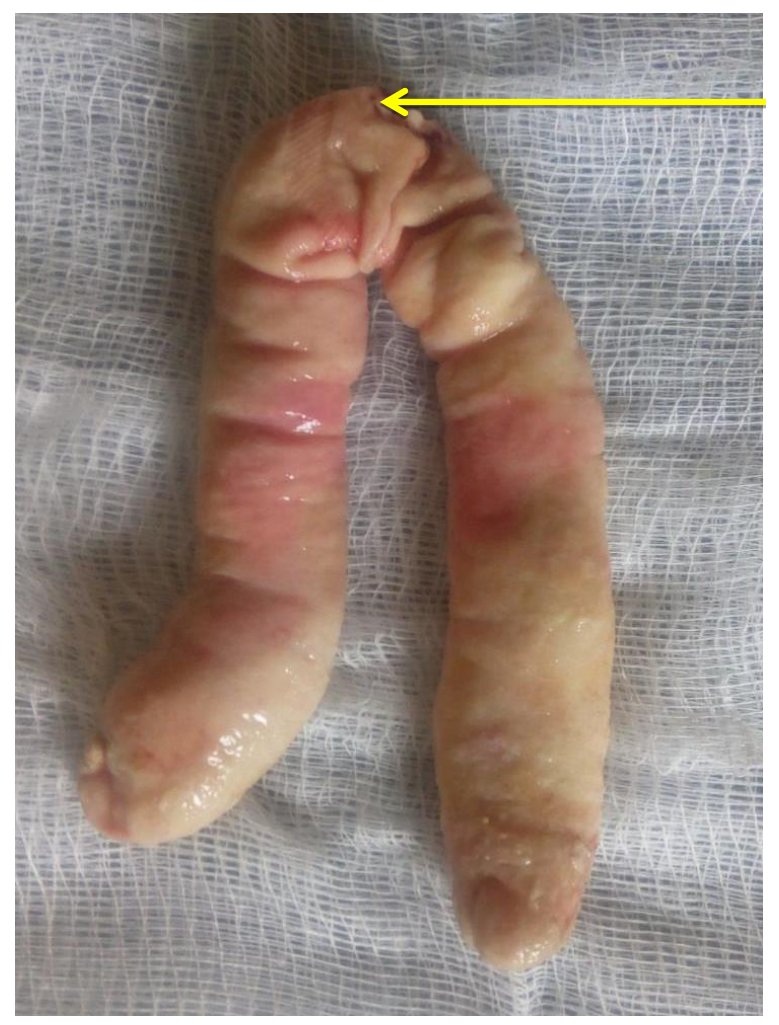

Fig. 4: Uterine horns after the hysterectomy. The arrow shows the level of the uterine body.

\section{Post-operative patient care}

Postoperative patient management included use of antibiotics (amoxicillin/clavulinic acid \{Noroclav; Norbrook\} at $12.5 \mathrm{mg} / \mathrm{kg}$ body weight $\mathrm{q} 12$, ceftriaxone $10 \%$ Injxone, Inject Care Parenterals $\}$ at $22 \mathrm{mg} / \mathrm{kg}$ body weight q12), Elizabethan collar, intravenous fluids administration and analgesia using phenylbutazone at $8 \mathrm{mg} / \mathrm{kg}$ body weight q.o.d (Phenylbutazone; Agrar). Since the cat had slightly pale mucous membranes, a single injection of iron dextran (Dawafer; Dawa) was done at 10mg/kg body weight intramuscularly. One day post-operatively, the cat was stable, alert, had good appetite, urinated normally and the external genitalia was clean with no discharge.

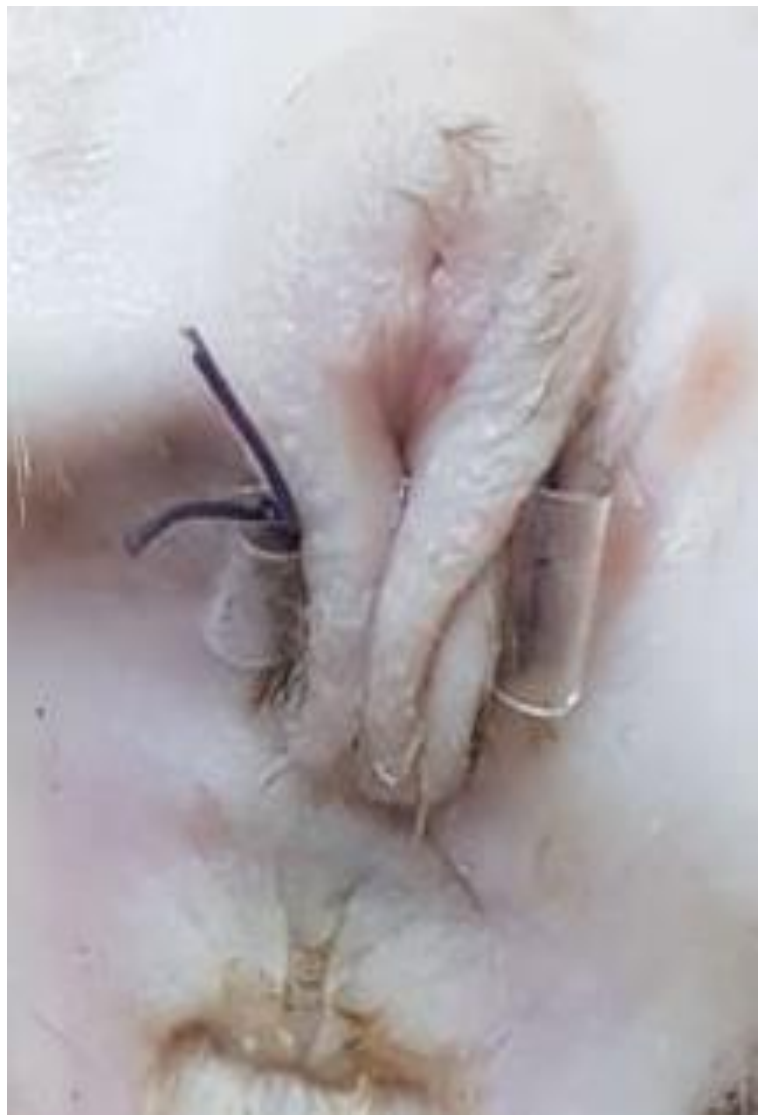

Fig. 5: A horizontal stay suture was placed to appose the vulval lips.

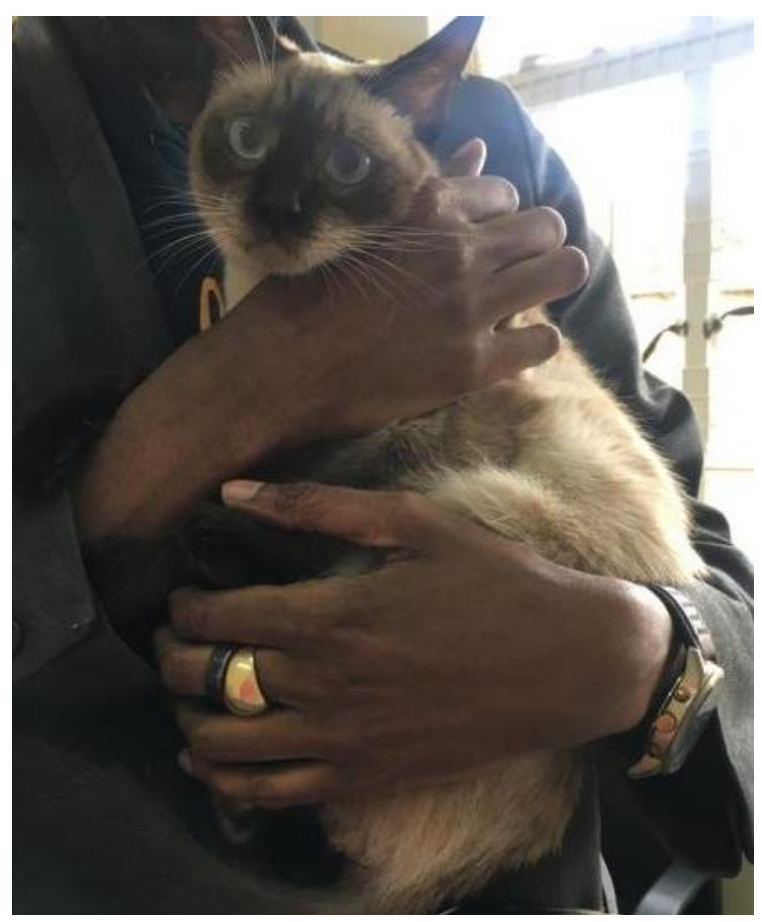

Fig. 6: The cat ten days post-operatively.

The patient was discharged on the second day with $2.5 \%$ cephalexin syrup (Rivalexin; Riva Pharma S.A.E) at $30 \mathrm{mg} / \mathrm{kg}$ body weight PO, q12 for 7 days. The outcome of the surgery was good with the cat recovering well and no complications which were reported by the owner (Figure 6). 


\section{DISCUSSION}

Uterine prolapse is a post-parturient complication that can occur immediately or up to $48 \mathrm{~h}$ after the last neonate is delivered (Deroy et al., 2015). In this case, the prolapse was noted by the client 24 hours after the last kitten was delivered. It may occur with protrusion of both horns from the vulva (bicornuate prolapse) or one part of the uterine body (Ucmak et al., 2018) and one horn (unicornuate prolapse) (Deroy et al., 2015). The uterine horn(s) may prolapse and reside in the cranial vagina or be everted through the vulva (MacPhail, 2013). In this case, the prolapse was bicornuate and both left and right uterine horns and the uterine body were visible from outside.

This condition may occur as a sequel of decreased myometrial tone; which may allow the uterus to evert towards the pelvic inlet. Prolonged queening as in this particular case; is one of the problems that might cause a dystocia and increased straining during the parturition process. This may probably lead to uterine prolapse. Purported risk factors that predispose cats to uterine prolapse include: prolonged labour, obesity, oversized fetus (Deroy et al., 2015); powerful oxytocin induced myometrial contraction during labour, extreme cervical dilatation, incomplete separation of the placental membranes and relaxation and stretching of the pelvic muscles. Other factors include severe tenesmus, uterine atony (Ucmak et al., 2018) and flaccid mesovaria (Nothling et al., 2002). In the present case, the causative factor identified was prolonged labour where the third kitten was delivered about 24 hours after the delivery of the second neonate. A pause of more than 4 hours between deliveries of kittens is abnormal and warrants examination of the queen (Rozanski and Rush, 2007).

Uterine prolapse is an obstetric emergency (Ozyurtlu and Kaya, 2004, Deroy et al., 2015, Jarolmasjed, 2017) as there is risk of uterine rupture and hemorrhage (Deroy et al., 2015); and should be aimed to facilitate management before accumulation of edema, mucosal trauma and contamination (Deroy et al., 2015). In this particular case, the cat was presented to the hospital a week later after the prolapse was noticed. The client may have assumed the protruding mass was normal during parturition and was giving time for it to resolve on its own. Contamination of the prolapsed tissue could be the likely cause of neutrophilia noted.

Depending of several factors such as severity of devitalization, damage, ischemia, and edema of the prolapsed tissue; there are various treatment methods that can be performed. They include: manual reduction, amputation of the prolapsed uterus, repositioning by abdominal palpation and local use of oxytocin and hyperosmotic serum infusion such as 50\% dextrose, ovariohysterectomy and manual reduction after celiotomy (Ozyurtlu and Kaya, 2005, Ucmak et al., 2018). Medical treatment is seldom successful (MacPhail, 2013, Jarolmasjed, 2017) and entails manual reduction of the prolapse. This method has several probable complications which include: urinary incontinence, urethral obstruction, uterine rupture, pyometra and cystic endometrial hyperplasia (Ucmak et al., 2018).

Ovariohysterectomy (OHS) is the recommended method of management if the uterus is heavily damaged, necrotic or if the ovarian vessels are ruptured (MacPhail, 2013, Deroy et al., 2015, Jarolmasjed, 2017). Ovariohysterectomy can be performed before or after manual reduction (Deroy et al., 2015). In this particular case, the prolapsed uterus was heavily contaminated and swollen to be pushed back into the abdominal cavity. Further, the uterus had areas of devitalization and was swollen since the duration of the prolapse was long; and therefore, manual reduction was impossible and a two staged ovariohysterectomy was the best option.

\section{Conclusions and recommendations}

Uterine prolapse in the present case might have been caused by a prolonged parturition which is one of the causes of dystocia in queens. Further, the prolapse was prolonged and the uterus had necrotic areas and was heavily contaminated.

I recommend that when the prolapsed uterus is swollen, damaged and necrotic, a two staged ovariohysterectomy should be chosen as the method of treatment and the outcome is good despite the duration of the condition.

\section{REFERENCES}

Bigliardi E, Ianni FD, Parmigiani E, et al., 2014. Complete uterine prolapse without uterine mucosal eversion in a queen. J Small Anim Prac, 55: 235-237.

Deroy C, Bismuth C and Carozzo C, 2015. Management of a complete uterine prolapse in a cat. J Feline Med Surg Open Reports, 1: 2055116915579681.

Jackson PGG, 2004. Postparturient problems in the dog and cat. Handbook of Veterinary obstetrics. $2^{\text {nd }}$ ed. Elsevier, pp: 234

Jarolmasjed S, 2017. Unusual case of utero-ovarian prolapse concurrent with cystocele in a queen. Iran J Vet Surg, 12: 69-73.

MacPhail CM, 2013. Surgery of the reproductive and genital systems, in: Fossum TW, Dewey CW, Horn CV, Johnson AL, Radlinsky MG, Schulz KS, Willard MD (editors), Small Animal Surgery. $4^{\text {th }}$ ed. St. Louis: Elsevier Mosby, pp: 826-827.

Mostachio GQ, Vicente WRR, Cardilli DJ, et al., 2008. Prolapso uterino em gata e retroflexão uterina em cadela. Ciência Animal Brasileira, 9: 801-805.

Nothling JO, Knesl O, Irons P, et al., 2002. Uterine prolapse with an interesting vascular anomaly in a cheetah: a case report. Theriogenology, 58: 1705-1712.

Ozyurtlu N and Kaya D, 2005. Unilateral uterine prolapse in a cat. Turkish J Vet Anim Sci, 29: 941-943.

Rozanski E and Rush J, 2007. Reproductive emergencies. Small Animal Emergency and Critical Care Medicine. Manson, London, pp: 183-185.

Sabuncu A, Dal GE, Enginler SÖ, et al., 2017. Feline unilateral uterine prolapse: a description of two cases. J Faculty Vet Med, Istanbul University, 43: 67-70

Sathiamoorthy T, Raja S, Thirumurugan K, et al., 2011. Unilateral uterine horn prolapse with retained fetus in a queen cat. Indian Vet J, 88: 120-121.

Senna NA, Farghali HA and Shalaby RKI, 2015. Some studies on feline genital system surgical affections (prevalence, histopathology and surgical interventions). Academic J Ani Dis, 4: 60-68.

Ucmak ZG, Ucmak M, Cetin AC et al., 2018. Uterine prolapse in a pregnant cat. Turkish J Vet Ani Sci, 42: 500-502.

Valentine MJ, Porte S, Chapwanya A, et al., 2016. Uterine prolapse with endometrial eversion in association with an unusual diffuse, polypoid, fibrosing perimetritis and parametritis in a cat. J Feline Med Surg open reports, 2: 2055116915626166. 